Session 1438

\title{
HELPING STUDENTS LEARN TO ORGANIZE AND MANAGE A DESIGN PROJECT
}

\author{
A.W. Fentiman, J.T. Demel, R. Boyd, K. Pugsley, P. Dutta \\ The Ohio State University
}

\section{Introduction}

As part of the NSF-sponsored Gateway Engineering Education Coalition program, some freshman engineering students at The Ohio State University participate in a three- or four-quarter integrated sequence of courses that culminates in a one-quarter team design project. Two groups of students have completed the team design project during the past year. The first group, consisting of students who were calculus-ready when they entered Ohio State in the fall of 1994, took the design course in Spring Quarter 1995 (their third quarter). The other group, students who were not calculus-ready when they entered Ohio State, took an additional quarter of math and physics courses before they began the design course in Autumn Quarter 1995 (their fourth quarter).

In the design class, teams of four or five students are required to build and program a robot to negotiate a $4 \mathrm{ft} x$ $9 \mathrm{ft}$ course with a hill in it, picking up blocks placed at prescribed locations and carrying them into the finish area. Figure 1 is a diagram of the course. Points are awarded for each block brought to the finish area. Teams can earn extra points by transferring blocks to an elevated bonus zone beyond the finish area. The robots are tested, both individually and in head-to-head competitions, at the end of the ten-week quarter.

Points earned in the individual runs and the head-to-head competition contribute to the team's course grade. Other activities that are graded throughout the quarter include written and oral reports and laboratory exercises related to various robot subsystems.

At the beginning of the design project, each team is required to prepare a detailed design schedule. The schedules are reviewed by the faculty and suggestions are made to help students prepare realistic schedules. Teams in the first pilot group (Spring 1995) were expected to follow their schedules, and faculty informally monitored their progress. However, no formal intermediate deadlines or milestones were set. All teams completed their robots in time for the competition, and all successfully carried at least one block into the finish area. But many of the teams worked nearly around the clock the day or two before the competition. Since the competition was near the end of the quarter when instructors in other courses were giving exams and other term projects were due, spending many hours on the design project had a negative effect on some students' grades in other courses. It was clear that students needed more help in organizing and managing their design projects. During the second pilot course (Autumn 1995), students were given more guidance in project organization and management. The methods used to help students learn how to organize and manage their design projects and some conclusions about the students' performance are presented in the remainder of this paper.

\section{Helping Students Organize a Project}

At the beginning of the team design project, students are asked to prepare a design schedule. A detailed, realistic schedule is crucial if the teams are to successfully complete their projects in the ten-week academic term. It is important that the students develop the schedule themselves so that they are forced to think about the tasks that must be done and their relationships to each other. However most students, particularly freshmen, have not had any experience with developing a schedule for a multi-task project and do not know how to begin. 
Faculty can help the students prepare the design schedule by outlining a process they can follow. The first step in the process is to list all of the tasks that need to be done to complete the project. Encourage students to think linearly, as though a single person were going to do the project and could do just one thing at a time. Every task should be listed. No detail should be omitted. Students, and many practicing engineers, often forget to include documentation tasks, such as progress reports or final reports, and need to be reminded to include them. Next, students identify the relationships among tasks, breaking tasks into subgroups and showing the order in which tasks within each subgroup need to be done. Then students can decide which groups of tasks can be done in parallel.

The next step is to estimate the time required for each task. Inexperienced students have difficulty with this step. It is often easier for students to start at the end. In general (for a ten-week quarter) the final product, including all subsystems or subparts, should be assembled one week before the due date. All subsystems should be completed at least one week before they are to be assembled in the final product to allow for testing of the subsystems. A completion date for each subsystem can then be established and a start date for each subsystem estimated. Students should be encouraged to include a "cushion" near the end of their schedule, in recognition of Murphy's Law. For example, they might set the deadline for completing all subsystems two and one-half weeks before the due date rather than just two weeks. Using this system, students will probably find that they need to meet many tight deadlines near the beginning of the quarter. They should be encouraged to push themselves hard at the beginning when other courses demand less of their time.

Finally, students can construct a weekly schedule showing which tasks will be done each week of the quarter. The person responsible for each task should be identified on the schedule. A typical schedule is shown in Figure 2. Having a particular person held publicly responsible for each task increases the chances that the task will be done on time and reasonably well. One negative aspect of having a single person responsible for a task is that that person will pay attention to the task. This can lead to disaster if that one person becomes ill or leaves the team. To avoid this problem, in the Ohio State design course, students are told that there should be a backup person familiar with each task and able to do that task if the person with primary responsibility is not available. Students are told that deadlines must be met, and no excuses will be accepted.

When the first draft of the design schedule is prepared, before the end of the first week of class, faculty members review each team's schedule to see if it is complete and realistic. Teams revise their schedules in accordance with faculty comments.

Two other bits of advice are given to student teams when they begin their scheduling exercise. First, they are told it is likely that their design schedules will have to be modified. Circumstances beyond their control will undoubtedly affect their schedules. Second, they are cautioned that a schedule is much more likely to be kept if all members of the team agree to it. If one person dictates a schedule for the team and makes assignments without consulting the other team members, the rest of the team will not feel committed to meeting the deadlines.

\section{Helping Students Manage a Project}

Once a good design schedule has been written, managing the project is largely a matter of adhering to the schedule. Students often find this difficult. The three primary reasons for this difficulty seem to be ( 1 ) failure to anticipate problems (to be expected due to inexperience), (2) procrastination, and (3) failure to do preliminary calculations and/or testing. Students can be warned about these problems, but usually, experience is the best teacher.

After students in the Spring 1995 team design course at Ohio State failed to stick to their design schedules, faculty teaching the course identified three ways to help students in the Autumn 1995 course do a better job of meeting deadlines.

The first method was to set intermediate milestones. The students were to build a robot that would navigate a course and pick up blocks. To build its robot, each team needed the same basic robot subsystems: a chassis, a drive train, a block retrieval system, and a sensor/controller package. In the syllabus for the course, a deadline was set for completion of each of those subsystems as well as for demonstrating minimal functioning of the 
assembled robot. On Friday of each week, each student team met with the faculty team to make a short presentation on their progress during the past week. They were required to demonstrate that the subsystem scheduled for completion that week worked. Meeting a deadline was worth a specified number points. The team received either the maximum number of points or no points depending upon whether or not the subsystem "worked" (i.e. met the published specifications). At the same time, teams were required to submit sketches of their subsystem and supporting calculations.

The second way that faculty prodded students to adhere to their schedules was to require them to produce a weekly schedule. On Monday, each team was to turn in a one-page form showing the tasks to be worked on that week, along with the names of the people responsible for the tasks and the completion dates. On the following Monday, students completed the last column on the form showing who actually did the task and the status of the task at the end of the week (e.g. finished, continuing, delayed, reassigned). Figure 3 is a sample weekly schedule.

The weekly schedules served several functions. First, they forced the students to think about and refer to their design schedules. Second, they gave students a simple way to modify or update their schedules. Finally, they helped the faculty to monitor and perhaps avert one of the most intractable problems with team design projects: people who do not carry their share of the load. When the names of students responsible for each task are put on a form each week and turned in, students are reminded of their duty to the team. The pressure of public commitment is sometimes enough to cause a student to do the work expected of him or her. If the student still fails to do the assigned task, at least the faculty have a record of which students shirked their responsibilities and can adjust the grades accordingly.

Finally, one week before the final competition, students participated in a preliminary competition. This was the third incentive for students to stay on schedule. In the preliminary competition, each team's robot was placed alone on the track and was to traverse the course, picking up blocks and taking them to the finish area. Points were awarded for getting to the finish area and for any blocks carried into that area. Each team had three timed trials, and the highest score of the three was the one recorded for grading purposes.

\section{Discussion and Conclusions}

Did setting intermediate deadlines and requiring weekly schedules keep all students from working late into the night before the final competition? No. However, all teams in the Autumn 1995 class did have working robots at least one week before the final competition, and all earned some points in the preliminary competition. Several teams in the Spring 1995 class (for which there was no preliminary competition) did not have working robots one week before the final deadline. Some students in the Autumn 1995 class commented that they appreciated the intermediate deadlines which helped them to pace their work throughout the quarter. Faculty noticed that several teams in the Autumn 1995 class did not work through the night before the final competition, and faculty did not hear complaints about work on the robots interfering with completing assignments in other courses.

General performance of the robots from the two classes (Spring 1995 and Autumn 1995) in the final competition was about the same. It was noted that, in both years, performance in the individual final competition (each robot put on the course alone) was better than in the head-to-head competition (two robots on the course at the same time). In the head-to-head test, the two robots often collided and did not seem to be programmed to quickly separate after the collision. In future years, the preliminary competition should include a head-to-head component so that students can develop strategies for that type of competition and program their robot controllers accordingly.

Students in the Autumn 1995 class certainly had more opportunities than the Spring 1995 class to develop and practice skills and techniques needed to organize and manage a project. All Autumn 1995 teams monitored their design schedules carefully, noted the impact of unanticipated problems (such as delays in receiving orders, absences of team members, and component failures), and modified their schedules as necessary. They made preliminary sketches and calculations for robot components, established performance requirements for those components, and conducted preliminary tests of the various robot subsystems to determine whether they met the requirements. In addition, the students learned how to meet deadlines. Every team in the Autumn 1995 class 
met all intermediate deadlines for completion of robot subsystems even though some of them had to make eneı minute changes in design in order to do so.

One final observation was that in several teams from the Autumn 1995 class, not all members were perceived to do their share of the work. This did not seem to be a major problem for the Spring 1995 class. The difference may be due to the normal variation from one group of students to another. However, it appeared that because students in the Autumn 1995 class had worked together for an entire year and had developed opinions of each others strengths and weaknesses, a few teams had some internal conflicts from the beginning of the design project. Work remains to be done on selecting teams in such a way that the conflicts are avoided or on providing students with techniques for minimizing the impact of personal differences on the quality of the final product. The students, themselves, have indicated that the later would be more practical.

\section{Acknowledgements}

This project of the Gateway Engineering Education Coalition, (NSF Award EEC-9444246), is supported in part by the Engineering Education and Centers Division of the National Science Foundation.

Bibliography

Boyer, et. al., Technical Graphics, John Wiley \& Sons, Inc., New York, New York, 1991.

et. al., "Assigning Students to Groups for Engineering Design Projects: A Comparison of Five Methods”, Journal of Engineering Education, Vol. 83, No. 3, pp 259-262, July 1994.

Byrd, and J. L. Hudgins, "Teaming in the Design Laboratory", Journal of Engineering Education, Vol. 84, No. 4, pp 335-342, October 1995.

J.H., Engineering Design Graphics, Fourth Edition, Addison- Wesley Publishing Company, Reading Massachusetts. 1983.

AUDEEN W. $\quad$ is an Assistant Professor in the Department of Civil and Environmental Engineering and Engineering Graphics at The Ohio State University. She is part of the team that has planned and taught the course in which students participating in the Gateway program at Ohio State design and build a robot.

JOHN T. DEMEL is a Professor in the Department of Civil and Environmental Engineering and Engineering Graphics at The Ohio State University. He is the Principal Investigator for projects conducted under the Gateway Engineering Education Coalition at Ohio State and also teaches several of the new courses developed as part of the Gateway project.

ROBERT BOYD is Program Director for Academic Affairs in the College of Engineering at The Ohio State University. He is a member of the team that has planned and taught the course in which engineering students participating in the Gateway Program at Ohio State design and build a robot.

KENNETH PUGSLEY is a mechanical engineer with several years of industrial experience. He is currently pursuing a Masters Degree in Education at Ohio State and working as a Graduate Teaching Assistant with the Gateway program, He has taken the lead in preparing and presenting many of the laboratory exercises included in the Gateway program.

PRABAL DUTTA in an undergraduate in Electrical Engineering at The Ohio State University He suggested that one of the From this projects at the end of the first year for the Gateway program be a robot, he helped to procure materials required to build the robots, and he served as a technical resource person for students in the Gateway program. 